\title{
A theoria do silencio no direito administrativo
}

Themistocles Brandão Cavalcanti (Procurador da Republica no Districto Federal)

A theoria do Silencio, como these juridica, tem sido pouco estudada entre nós, e, si o tem sido pouco no terreno do direito privado, onde mais numerosas são as monographias e os escripiós juridicos, pode-se dizer que, no campo do direito publico, e especialmente no do direito administrativo, tem sido de todo abandonada.

Merece, no entretanto, o assumpto, algumas palavras, notas á margem dos estudos do direito administrativo, pondo-se em evidencia, antes de tudo, a feição pratica da these.

Como pode o Silencio constituir manifestação da vontade?

Quando pode o Silencio ser considerado, tacitamente, como manifestação dessa vontade?

Quaes os effeitos do Silencio, no direito administrativo?

Como deve ser considerada a falta de manifestação da vontade?

São esses os aspectos mais interessantes da doutrina.

Quando se fala em manifestação da vontade, presuppõese uma affirmação, uma declaração escripta ou oral, por meio da qual se verifica o assentimento ou a negação, a concordancia ou a discordancia.

Nesse caso, a declaração ou affirmação constitue manifestação expressa da vontade. Quando, porém, é provocada a manifestação e a pessôa conserva-se em silencio, como deve ser interpretado esse Silencio? 
Quando deve elle ser tido como concordancia, ou discordancia, tacita?

O direito civil tem procurado solver as questões relacionadas com o Silencio, e um illustre Juiz do Districto Federal, dr. Serpa Lopes, reuniu em uma these, intitulada "Do Silencio como Manifestação da Vontade", estudos do maior interesse.

O direito romano já havia procurado resolver, com as suas formulas e sentenças lapidares, esses problemas.

O nosso velho proverbio - Quem cala, consente - exprime, apenas, o mesmo sentido daquella sentença: "Qui tacet, quum loqui potuit et debuit, consentire videtur", que, no entretanto, é mais sabia e menos categorica.

Desta ultima sentença, porém, partiu a doutrina preponderante com as restricções e reticencias nella propria contidas.

A applicação do principio não tem tido o rigor que, apparentemente, poderia ter, diante dos seus termos. Considera-se, todavia, que o Silencio equivale ao consentimento, quando a bôa fé ou a razão pratica teriam requerido uma opposição, caso não houvesse concordancia (Espindola, Systema de Direito Civil Brasileiro, vol. I, p. 531), (Dernburg, Pandette, ed. ital., vol. I, § 98).

Outros trechos podem, igualmente, ser mencionados, relativamente ao mesmo assumpto, ora applicaveis ao processo e a confissão in jure, ora ao direito civil.

A verdade estará, ainda, com a outra norma juridica, que affirma que o Silencio por si só nada significa: "Qui tacet neque negat, neque utique facetur".

Sobre este assumpto, devem ser consultados os civilistas como Demogue, "Traité des Obligations en général", vol. I, p. 302; Capitant, "Introduction à l'Etude du Droit Civil", p. 282; etc.

$\mathrm{Si}$, no campo do direito privado, as questões relativas á manifestação da vontade e suas consequencias são de facil evolução, porque é muito mais simples objectivar a personalidade do Homem, ou das pessôas juridicas de direito 
privado, quando se trata do Estado, porém, essa personalidade vai se diluindo por uma infinidade de representantes, a quem cabe manifestar a vontade.

As formas de sua manifestação são mais complexas; dependem, muitas vezes, do concurso de diversas autoridades, de formalidades burocraticas, indispensaveis á determinação da vontade do Estado, por meio de um ou mais orgãos competentes.

O problema tem, assim, outros aspectos. E' preciso, por isso mesmo, não confundir a inercia da administração, na defeza dos direitos seus ou da collectividade, com o Silencio na decisão, provocada por terceiros.

No primeiro caso, pode o silencio, a inercia, a falta de iniciativa importar na decadencia do direito. No segundo, não implica o silencio, necessariamente, no reconhecimento tacito de um direito.

Assim, na primeira hypothese, a falta do exercicio do poder de policia, de medidas coercitivas, de restricções ao exercicio de direitos, quanto á maneira e á forma de pratical-os, implicará, tacitamente, no consentimento.

Mas a falta de despacho em um pedido, em um requerimento, não pode ser considerada assentimento tacito, reconhecimento implicito da legitimidade da pretenção de terceiros, perante o Estado ou a administração.

Na França, na Italia, na Argentina, e em outros paizes, o silencio da administração, quanto ás suas consequencias juridicas, tem sido regulamentado pela lei, especialmente pela lei processual administrativa, como veremos em seguida.

Condensando os diversos principios que regulam o assumpto, Velasco (El Acto Administrativo, p. 206) formula as seguintes regras, a saber:

$1^{\circ}$ - $\mathrm{O}$ silencio tem que estar previsto ou interpretado na lei. Sua significação propria não deriva de actos ou de omissões, a menos que lhes tenha outorgado a lei uma significação determinada. 
2. - Omittir um acto de natureza discricionaria não tem significação juridica alguma; é um acto indifferente ao direito.

$3 .^{\circ}$ - Por conseguinte, a noção do silencio administrativo é uma noção empirica, que afasta toda regra abstracta.

4. ${ }^{\circ}$ - Manifesta-se deante da faculdade-poder, visto como, deante da faculdade-dever, deve-se considerar mera abstenção. Nesse caso do silencio, a administração pode falar, mas não tem o dever de fazel-o. Caracterisa-se, tambem, porque sómente apparece nos actos requeridos, e não nos expontaneos, que o proprio conceito elimina.

Essas regras, porém, teem um valor relativo, porque, como o proprio autor observa, não é possivel predeterminar as consequencias deste ou daquelle procedimento do Estado em suas variadissimas manifestações.

Vamos, assim, examinar algumas hypotheses mais interessantes:

I - A falta de despacho nos recursos interpostos nos processos administrativos importará, tacitamente, na confirmação da decisão?

Quid, si a autoridade administrativa não proferir a sua decisão dentro do prazo fixado pela lei?

Com relação a estas questões, as nossas leis administrativas, até agora, nada contêm que possa orientar uma opinião decisiva.

O Professor Rafael Bielsa, no Projecto do Codigo do Contencioso Administrativo da Provincia de Santa Fe, na Argentina, dispôz no art. 144:

"Art. 144 - El Poder ejecutivo dictará resolución dentro de los quince dias siguientes al de promoción del recurso si no hubiese prueba, y de treinta dias siguientes al decreto de clausura del término de prueba o de la presentación del in- 
forme. Si el Poder ejecutivo no resolviere en ese término se considerará que ha rechazado el recurso".

Estudando o assumpto, escreveu o mesmo autor:

"En caso de silencio de la Administración pública ante la reclamación del interesado, esta reclamación debe tenerse por tácitamente rechazada si pasado un plazo determinado no hay decisión expresa. Ese plazo debe ser uniforme en cada esfera administrativa: nacional, provincial ( $y$, comprendida en ésta, la comunal)"

E em outro trecho da mesma obra:

"La Administración pública tiene un plazo legal para decidir, y su silencio, pasado ese plazo, se considera como denegación tácita, por lo que entonces el trámite del recurso procede como si hubiera pronunciamiento contrario"

(Ideas Generales sobre lo Contencioso Administrativo)

No direito francez, as duvidas foram eliminadas pela lei de 17 de julho 1900, que considerou o silencio da administração, nos casos de recurso para o Conselho de Estado, como simples recusa, indeferimento. (Roger Bonnard, Précis de Droit Administratif, p. 195), (Waline, Manuel Elémentaire de Droit Administratif, p. 96).

No direito italiano, applicam-se os mesmos principios, devendo se considerar o assentimento tacito como excepção, conforme se vê na excellente obra de Leonidas Ragnisco, "I Ricorsi Amministrattivi" (p. 91).

A lei de 3 de março 1934, naquelle paiz, em materia de recurso administrativo, formulou expressamente a regra de que o silencio persistente e continuo da administração, para. 
pronunciar-se a respeito de um recurso hierarchico, deverse-á ter como confirmação do acto, e, portanto, a denegação do recurso (Ragnisco, op. cit., p. 253). (Pode-se consultar tambem sobre este assumpto, a numerosa bibliographia alli existente, notadamente as seguintes obras, que apenas indicamos para não alongar este trabalho: Raneletti, Le Guarantigie della Giustizia della Pubblica Amministrazione; Zanobini, Corso di Diritto Amministrattivo, 1938, vol. II, p. 119; Borsi, La Giustizia Amministrattiva, p. 75; o mesmo, Giurisprudenza Italiana, 1903, vol. 61; Ugo Forti, Diritto Amministrattivo, vol. II, p. 165; La Torre, Nozioni di Diritto Amministrattivo, 2.a ed., p. 201; Rivista di Diritto Pubblico, 1933, vol. II, p. 75; Rivista di Diritto Processuale e Civile, n. 2, 1932).

Não temos, em nosso direito, como dissemos, nenhuma disposição legal que regule definitivamente o assumpto, embora certos regulamentos, como o do imposto de renda, prescrevam um prazo dentro do qual devem ser proferidas as decisões administrativas, sem comtudo impôr qualquer sancção.

Pode attribuir-se essa deficiencia do nosso processo administrativo á falta de contencioso administrativo, que presuppõe maior rigidez das formulas processuaes, e respeito a prazos e outras exigencias, muito approximadas daquellas de natureza judicial (Ribas, Direito Administrativo, pags. 137 e seguintes; Uruguay, Ensaios sobre Direito Administrativo, vol. I, pags. 173 e seguintes).

Procurando codificar o processo administrativo, uniformisando as normas processuaes, tivemos opportunidade de estudar o assumpto, dispondo sobre os diversos prazos para serem proferidas as decisões administrativas, e determinando as consequencias juridicas decorrentes da demora ou do excesso do prazo.

O principio geral alli firmado, como se verá em publicação proxima, é o da confirmação tacita da decisão recorrida, em virtude do silencio prolongado, e o da remessa automatica do processo á autoridade hierarchicamente su- 
perior, pelo excesso do prazo para proferir a decisão por parte da autoridade hierarchicamente inferior.

A verdade é que, direito constituido, nada existe até agora entre nós.

II - Outra consequencia do silencio prolongado da administração (falta de decisão ou despacho) é aquella que diz com o curso da prescripção extinctiva.

A jurisprudencia italiana tem decidido que a demora no despacho importa no indeferimento do recurso, permittindo, no entretanto, outras vias para reforma das decisões das autoridades hierarchicamente inferiores.

Em nosso direito, o unico recurso cabivel é o judicial, por meio, ou da propositura da acção competente, ou de simples notificação, que trazem sempre como consequencia, nos termos do Codigo Civil, a suspensão do curso da prescripção.

Pode-se figurar, tambem, a hypothese de ser a divida liquida e certa e o funccionario demorar-se no pagamento ou no despacho do pedido da parte credora do Estado. Neste caso, pode-se verificar, excepcionalmente, a suspensão do curso da prescripção, por meio de simples reclamação administrativa.

Não prevê a lei, porém, termo prefixado para o despacho da autoridade administrativa, cabendo á parte o direito de suspender o curso da prescripção dentro do prazo geral fixado pelo Codigo Civil para a prescripção das dividas passivas da União, Estados e Municipios.

A lei n. ${ }^{\circ} 5.761$, de 25 de junho de 1930, e o Dec. de 6 de janeiro 1932 determinaram as condições em que se poderia dar interrupção da prescripção por via administrativa, quando se tratar de divida liquida e certa, cujo pagamento ou despacho depender da diligencia da autoridade administrativa.

Essa é uma das hypotheses em que as consequencias do silencio estão previstas pela lei e regulamentadas, embora deficientemente. 
III - Outra hypothese interessante é aquella prevista por certos autores com relação á inercia da administração, a sua demora em provêr certos cargos publicos ou em reconhecer o direito ao accesso de determinados funccionarios.

Encontram-se, notadamente, no direito italiano, algumas manifestações da jurisprudencia do Conselho de Estado, nas quaes foram reconhecidos direitos aos funccionarios, cujo accesso estava assegurado pela lei, tendo sido fixado um prazo dentro do qual deveria a autoridade administrativa praticar o acto de promoção (Rivista di Diritto Pubblico, 1932, vol. I, pags. 434 e seguintes).

Em nosso direito, nada justifica a constituição em móra da administração ou a creação de sancções administrativas em consequencia da demora e do silencio, em reconhecer o direito do funccionario á promoção, licença, ou outra qualquer vantagem, a menos que determine a lei prazo para ser proferida a decisão.

IV - Poderiamos mencionar alguns casos concretos que teem merecido a apreciação do Poder Judiciario. Limitarnos-emos, porém, a dous :

1.') Em certos casos de habeas-corpus, a autoridade coactora não satisfaz, em tempo opportuno, o pedido de informações. Tem admittido a jurisprudencia do Supremo Tribunal Federal que o silencio, nesses casos, silencio reiterado e manifesto, importa no reconhecimento tacito da reclamação judicial.

Ja se vê que, nestes casos, esta sancção representa um meio coercitivo usado para obrigar a autoridade a prestar a informação. Nada justifica considerar-se o silencio, ahi, como confissão.

Caso, porém, esteja a autoridade conscientemente convencida da legitimidade do seu acto, cabe-lhe justifical-o perante o Poder Judiciario.

Quando se trata de mandado de segurança, nada aconselharia a applicação desse principio, visto como, ao representante da pessôa juridica de direito publico interessada, compete, tambem, a defeza do acto impugnado. 
2..$^{\circ}$ Finalmente, podemos mencionar um outro caso, e do maior interesse: a falta de despacho em um pedido de certidão, por parte do funccionario.

Esta hypothese, embora revestida de uma modalidade peculiar, de recusa, foi objecto de uma decisão do Supremo Tribunal Federal, confirmatoria de uma brilhante sentença do Juiz Castro Nunes, conforme se vê em sua Monographia sobre o Mandado de Segurança, p. 412.

Reconheceu o Tribunal o direito certo e incontestavel á certidão, de accordo com o disposto na Constituição de 1934, independentemente de motivação do pedido.

Este direito certo e incontestavel, contraría a hypothese de que o silencio da administração importa no reconhecimento ou negação do direito; constitue, antes, uma falta attribuivel ao funccionario, que pode coagido a praticar o acto por meios coercitivos, isto é, judicialmente.

Figuramos, assim, uma hypothese em que o silencio não importa em manifestação da vontade, mas apenas na inercia e displicencia da autoridade administrativa, hypothese, infelizmente, muito commum.

Estas ligeiras notas sobre um assumpto pouco estudado, em geral, teem por fim, antes de tudo, lembrar a existencia de uma these que merece, pelas suas consequencias, uma solução legislativa. 